The Journal of SPORT, 2020, 8(1), 56-75

(C) Kent State University

\title{
A Preliminary Investigation into Collegiate Student- Athletes' Attitudes Towards Athletic Trainers and Sport Psychology Consultants
}

\author{
Kenneth Ildefonso \\ University of Wisconsin - Milwaukee \\ Jedediah Blanton \\ University of Tennessee \\ Cheryl Durwin \\ Southern Connecticut State University \\ Monna Arvinen-Barrow \\ University of Wisconsin - Milwaukee \\ Cindra Kamphoff \\ Minnesota State University, Mankato
}




\begin{abstract}
To investigate if athletes' attitudes toward athletic trainers and sport psychology consultants differ considering nature of athletic ability beliefs and previous experiences with these professionals; collegiate student-athletes $(n=114$ male, $n=81$ female, $M$ age $=19.77, S D=1.43$ ) completed the Conceptions of the Nature of Athletic Ability Questionnaire-2 (Biddle, Wang, Chatzisarantis, \& Spray, 2003), Attitudes Toward Athletic Trainers-Form (modified from the Attitudes toward Physiotherapist-Form; Arvinen-Barrow, Clement, \& Bayes, 2012), and the Sport Psychology Attitudes Revised-Form (Martin, Kellman, Lavallee, \& Page, 2002). Multiple analyses of variance revealed small statistically significant mean differences in attitudes considering ability beliefs, previous athletic training, and sport psychology experiences. Athletes with previous athletic training experience were less confident in their athletic trainer than those without such experience. In contrast, athletes with previous sport psychology experience were more confident in their consultant than those without such experiences. Results suggest athletes' attitudes towards helping professionals may be partially influenced by subjective norms and expectations about the nature of such relationships.
\end{abstract}

\title{
Introduction
}

In collegiate athletics, sports medicine professionals such as athletic trainers provide injury prevention and management services for athletes (Brumels $\&$ Beach, 2008). Less common, but growing in interest, is the provision of psychological services, provided by sport psychology consultants (Filion, Munroe-Chandler, \& Loughead, 2019; Fortin-Guichard, Boudreault, Gagnon, \& Trottier, 2018). Given the importance of providing patient-centered holistic care within helping professions, a limited body of literature has attempted to investigate the role of patient/client attitudes towards these professionals (e.g., Arvinen-Barrow, Clement, \& Bayes, 2012; Harwood \& Woolway, 2015). Attitudes are generally defined as "psychological tendencies that are expressed by evaluating a particular entity with some degree of favor or disfavor" (Eagly \& Chaiken, 1993, p. 1). Martin, Kellman, Lavallee, and Page (2002) further explained that in sport, athletes can develop a range of attitudes toward sportrelated professionals in terms of their professional skillset and/or personal characteristics, to name a few.

Understanding attitudes would be beneficial, as the theory of planned behavior (Ajzen, 1991) posited, attitudes play a significant role in individuals' resultant behaviors such as seeking and adhering to treatment (Rich, Brandes, Mullan, \& Hagger, 2015). Specifically, the theory of planned behavior (Ajzen, 
1991) suggested an individual's intentions to engage in a behavior are more likely to occur when accompanied with positive attitudes. The theory proposed that human behavior is guided by a range of beliefs such as attitudes toward a behavior (i.e., the extent of one's favor or disfavor toward a given-behavior), subjective norms (i.e., perceived socially acceptable conditions) and perceived behavioral control (i.e., perceived ability to perform a behavior; Ajzen, 1991).

Previous research suggests patients' attitudes toward healthcare professionals can influence patients' treatment-related behaviors (Sande-Meijide et al., 2019; Wyer, Earll, Joseph, \& Harrison, 2001). These attitudes have also been found to be influenced by multiple factors such as current health condition and social support (Tsimtsiou, Kirana, \& Hatzichristou, 2014). However, despite the importance of providing patient-centered services in athletic training and sport psychology, knowledge of collegiate athletes' attitudes towards these service providers is lacking (Arvinen-Barrow et al., 2012; Martin et al., 2002).

Within athletic populations, it is known that male and female athletes differ in their attitudes towards doping in sport (Morente-Sanchez \& Zabala, 2013), skin cancer (Hobbs, Nahar, Ford, Bass, \& Brodell, 2014), help seeking for mental illness (Barnard, 2016), sport psychology consulting (Martin, Lavallee, Kellman, \& Page, 2004), and working with physiotherapists (Arvinen-Barrow et al., 2012). Thus far, no known studies investigating athletes' attitudes toward athletic trainers exists. However, given the similarities in job tasks between the physiotherapists treating injured athletes in the UK and athletic trainers in the US, some inferences from the Arvinen-Barrow et al. (2012) study can be made.

The results from the Arvinen-Barrow et al. (2012) study indicated that injured athletes' previous experiences with a physiotherapist did not significantly influence athletes' attitudes toward the said professional. In contrast, Anderson, Hodge, Lavallee, and Martin (2004) found the opposite to be true among athlete's attitudes toward sport psychology consultants; athletes with previous experiences held less negative attitudes, and were more confident in their sport psychology consultant than athletes without previous experiences. Recently, Harwood and Woolway (2015) found athletes to prefer sport psychology consultants with high sport-specific knowledge and strong interpersonal skills. However, these two studies (Anderson et al., 2004; Harwood \& Woolway, 2015) utilized different questionnaires, making direct comparison of the results difficult.

The theory of planned behavior also suggested that individuals' attitudes toward behavior are determined by their personal beliefs which, together with perceived behavioral control can influence one's intentions and subsequent behavior (Ajzen, 2011). Existing literature suggests when athletes believe the nature of their own athletic ability is fixed and unchangeable, athletes are likely to think asking for help demonstrates vulnerability (Biddle, Wang, Chatzisarantis, \& Spray, 2003). Athletes who believe their athletic ability to be malleable (i.e., 
learned) are likely to think supportive relationships increase the chance of success (Biddle et al., 2003). Research has shown that athletes typically hold both beliefs simultaneously, but the extent of each belief varies in strength (Chian \& Wang, 2008). Feelings of vulnerability and the desire to seek supportive relationships may influence athletes help seeking attitudes in sport (Biddle et al., 2003). Higher levels of perceived athletic identity have also been associated with rehabilitation over-adherence (Hilliard, Blom, Hankemeier, \& Bolin, 2016), thus suggesting that athletic identity can influence one's behaviors during injury rehabilitation and ultimately have negative effects on the overall rehabilitation outcomes (Granquist $\&$ Brewer, 2013). This study aims to fill the research gaps identified above by investigating whether athletes' attitudes towards athletic trainers and sport psychology consultants differ considering the nature of athletic ability beliefs and previous experiences with the aforementioned professionals.

\section{Materials and Methods}

\section{Participants and Procedure}

A convenience sample of 195 student-athletes $(n=114$ male, $n=81$ female, $M$ age $=19.77, S D=1.43$ years) were recruited from a National Collegiate Athletic Association (NCAA) Division II University where studentathletes have access to both athletic trainers and sport psychology professionals (See Table 1). Institutional review board (IRB) approval was obtained from the university where the study was conducted. Following IRB approval, initial contact was made via email with all head athletic coaches $(n=19)$ requesting permission to ask each team to participate in the study. Seven coaches replied (response rate of $36.8 \%$ ) and agreed to a team meeting. These meetings allowed the researcher to inform the athletes about the study and their rights as participants. Those who volunteered to take part, read the consent form, and completed the Conceptions of the Nature of Athletic Ability Questionnaire-2, Attitudes toward Athletic Trainers-Form, and the Sport Psychology Attitudes Revised-Form in counter-balanced order as in previous research (Hilliard, Redmond, \& Watson, 2019). The primary researcher was a licensed athletic trainer for the university where the data collection took place; therefore, the IRB prohibited the signing of consent forms and required the author to leave the room during questionnaire completion to ensure participant anonymity. The meetings and completion of questionnaires lasted approximately 15 minutes per team. 
Table 1

Demographics of the Sample

\begin{tabular}{|lll|}
\hline Gender & $n$ & $\%$ \\
Male & 114 & 58.46 \\
Female & 81 & 41.54 \\
& & \\
Freshman & 61 & 31.28 \\
Sophomore & 57 & 29.23 \\
Junior & 41 & 21.03 \\
Senior & 31 & 15.90 \\
Second-year senior & 4 & 2.05 \\
Graduate & 1 & 0.51 \\
Men's sports & & \\
Track \& field & 47 & 24.10 \\
Baseball & 30 & 15.38 \\
Football & 37 & 18.97 \\
Women's sports & & \\
Track \& field & 19 & 9.74 \\
Golf & 9 & 4.61 \\
Volleyball & 11 & 5.64 \\
Cheerleading & 25 & 12.82 \\
Cross country & 17 & 8.72 \\
Athletes' previous experience & & \\
Athletic training but not sport psychology consulting & 60 & 30.77 \\
Sport psychology consulting but not athletic training & 6 & 3.08 \\
Athletic training and sport psychology consulting & 97 & 49.74 \\
Neither athletic training nor sport psychology consulting & 25 & 12.82 \\
\hline
\end{tabular}

\section{Conceptions of the Nature of Athletic Ability Questionnaire-2}

The Conceptions of the Nature of Athletic Ability Questionnaire-2 (Biddle et al., 2003) is a 12-item questionnaire which assesses the degrees to which an individual's beliefs concerning the nature of athletic ability are entity (i.e., fixed) and incremental (i.e., malleable) on a 5-point Likert scale from 1 (strongly disagree) to 5 (strongly agree). Entity beliefs are comprised of two subscales: (1) stable (i.e., belief that one's athletic ability is unchangeable) and (2) gift (i.e., belief that one's athletic ability is a gift and something one is born with). 
Incremental beliefs are comprised of two subscales: (1) learning (i.e., belief that one's athletic ability is a result of learning), and (2) improvement (i.e., belief that one's athletic ability can improve with hard work). Example items include, "you need to have certain 'gifts' to be good at sport" and "if you work hard at it, you will always get better."

The Conceptions of the Nature of Athletic Ability Questionnaire-2 has been found to be reliable, and to have factorial, convergent and discriminant validity (Biddle et al., 2003) with Cronbach's alpha coefficients ranging from .73 to .79 for its subscales (Wang \& Biddle, 2003). Several studies have shown support for the multidimensional hierarchical structure across multiple age groups, gender, and sample sizes (Biddle et al., 2003; Spray, Wang, Biddle, Chatzisarantis, \& Warburton, 2006).

\section{Attitudes toward Athletic Trainers-Form}

The questionnaire utilized in this study was an adaptation of the Attitudes toward Physiotherapist-Form (Arvinen-Barrow et al., 2012) which, was originally adapted from the Sport Psychology Attitudes Revised-Form (Martin et al., 2002). The original form was developed to assess athletes' attitudes towards sport psychology consultants, later modified to assess athletes' attitudes toward physiotherapists. For the purposes of this study, the title "physiotherapist" was replaced with "athletic trainer" to better align with the American nomenclature for the profession.

The Attitudes toward Athletic Trainers-Form is a 25-item questionnaire which assesses an individual's attitudes toward working with an athletic trainer on a 7-point Likert scale ranging from 1 (strongly disagree) to 7 (strongly agree). The form consists of four subscales: (1) confidence in athletic training (i.e., belief an athletic trainer can facilitate proper recovery), (2) cultural preference (i.e., degree to which the individual identifies with the athletic trainer's race, culture, and ethnicity), (3) personal openness (i.e., willingness to take part in the associated tasks of an athletic trainer), and (4) stigma tolerance (i.e., negative beliefs in athletic training). Example items include "having seen an athletic trainer is bad for an athlete's reputation" and "an athletic trainer could help me fine-tune my sport performance." The measure has demonstrated acceptable to minimally acceptable levels of internal consistency with Cronbach's alpha coefficients ranging from .68 to .87 (Arvinen-Barrow et al., 2012). 


\section{Sport Psychology Attitudes Revised-Form (Martin et al., 2002)}

The Sport Psychology Attitudes Revised-Form is a refinement of the 50item Attitudes toward Seeking Sport Psychology Consultation Questionnaire (Martin, Wrisberg, Beitel, \& Lounsbury, 1997). The Sport Psychology Attitudes Revised-Form has 25-items, assessing an individual's attitudes toward working with a sport psychology consultant on a 7-point Likert scale from 1 (strongly disagree) to 7 (strongly agree). The form consists of four subscales: (1) confidence in sport psychology consulting (i.e., belief a sport psychology consultant can facilitate performance), (2) cultural preference (i.e., degree to which the individual identifies with the sport psychology consultant's race, culture, and ethnicity) (3) personal openness (i.e., willingness to take part in the associated tasks assigned by a sport psychology consultant), and (4) stigma tolerance (i.e., negative beliefs in sport psychology consulting). Example items include "having seen a sport psychology consultant is bad for an athlete's reputation" and "a sport psychology consultant could help me fine-tune my sport performance." The measure has demonstrated appropriate levels of Cronbach's alpha coefficients ranging from .61 to .88 (Anderson et al., 2004; Lavallee, Jennings, Anderson, \& Martin, 2005). The subscales of cultural preference and personal openness appear to have low reliability coefficients; however, given the small number of items that represent each subscale, the original author has indicated this to be tolerable (Martin et al., 2002).

\section{Screening Data}

Following data collection, 200 surveys were reviewed and screened by the primary researcher and descriptive statistical analyses (frequencies, means, and standard deviations) were calculated using SPSS statistical package (version 20.0). Four surveys were removed due to one or more incomplete questionnaires, and one was removed due to selecting neutral for all items, conflicting with the participant's information provided on the demographic section. Of the 195 surveys used in the final analyses, missing variables $(n=26)$ were replaced with relevant subscale means. This method (i.e., single imputation) has been proposed as appropriate for managing small amounts of missing survey data (Zang, 2016).

\section{Design}

The study adopted a cross sectional survey design. The first independent variable (beliefs concerning the nature of athletic ability) was comprised following the cluster analysis decision process recommendations of Hair, Black, Babin, and Anderson (2010). The second independent variable was constructed 
by dichotomizing athletes' previous athletic trainer experiences (yes/no) and sport psychology consultant experiences (yes/no) into groups: previous experience with athletic trainer, no previous experience with athletic trainer, previous experience with sport psychology consultant, no previous experience with sport psychology consultant. The dependent variables were the subscale scores from the Attitudes toward Athletic Trainers-Form and the Sport Psychology Attitudes Revised-Form.

\section{Calculations}

The clustering procedures were adopted from previous research (Chian \& Wang, 2008). The dendrogram and agglomeration coefficient of the hierarchical cluster analysis revealed a two-cluster solution as most appropriate. To confirm the clusters, a k-means clustering method was conducted. A one-way multivariate analysis of variance (MANOVA) found the final solution to be statistically significant $F(4,190)=111.765, P=.000 ;$ Wilk's $\lambda=.30 ; \eta^{2}=.702$.

To investigate athletes' beliefs concerning the nature of athletic ability and their attitudes toward athletic trainers and sport psychology consultants, the dichotomized previous experience variables (athletic trainer/sport psychology consultant) were explored by conducting two separate one-way multiple analyses of variance (MANOVAs). To investigate any possible differences in athletes' attitudes toward athletic trainers and/or sport psychology consultants based on their previous experiences with these professionals, we used two separate MANOVAs. The significance level was set to $\alpha=.05$ for main effects and $\alpha=$ .013 for univariate post hoc testing (i.e., Bonferroni adjustment).

\section{Results}

\section{Reliability}

Table 2 displays the reliability coefficients for each measure. The Cronbach's alphas calculated for the Nature of Athletic Ability Questionnaire-2 (Moreno-Murcia, Gimeno, Galindo, Hernández, \& Buñuel, 2014; Wang \& Biddle, 2003), Attitudes toward Athletic Trainers-Form (Arvinen-Barrow et al., 2012), and the Sport Psychology Attitudes Revised-Form (Martin et al., 2002), were consistent with previous research. Although several Sport Psychology Attitudes Revised-Form subscale alphas' were low, when considering the robust factor structure of the entire measure, these low subscale scores are suggested to be tolerable (Martin et al., 2002). 
Table 2

Reliability Coefficients for each Measure

\begin{tabular}{|cc|}
\hline Subscale & $\alpha$ \\
\hline Conceptions of the Nature of Athletic Ability-Questionnaire & $.61^{*}$ \\
Stable & .78 \\
Gift & .82 \\
Learning & $.66^{*}$ \\
Improvement & \\
Attitudes Toward Athletic Trainer-Form & .83 \\
Confidence & .72 \\
Cultural preference & $.64^{*}$ \\
Personal openness & .87 \\
Stigma tolerance & \\
Sport Psychology Attitudes Revised-Form & .90 \\
Confidence & $.68^{*}$ \\
Cultural preference & $.57^{*}$ \\
Personal openness & .86 \\
Stigma tolerance & \\
\hline
\end{tabular}

*Low level of internal consistency

\section{Descriptive Statistics}

Table 3 displays the means and standard deviations for the subscales of all three measures. Previous research has described high scores of the Conceptions of the Nature of Athletic Ability Questionnaire-2 greater than four and low scores less than three (Wang \& Koh, 2006). High scores of the Attitudes toward Athletic Trainers-Form are those closer to the score of seven (Arvinen-Barrow et al., 2012). Note that scores for personal openness were calculated in reverse coding to measure the participant's willingness to take part in athletic training associated tasks. Previous research has described Sport Psychology Attitudes Revised-Form results as low (score of three), moderate (score of four), and high (closer to seven; Lavallee et al., 2005). 
Table 3

Means and Standard Deviations of the Questionnaires' Subscales

\begin{tabular}{|lll|}
\hline Conceptions of the Nature of Athletic Ability-Questionnaire & $M$ & $S D$ \\
\hline Stable & 2.22 & 0.78 \\
Gift & 2.81 & 0.95 \\
Learning & 3.80 & 0.92 \\
Improvement & 4.50 & 0.54 \\
\hline Attitudes Toward Athletic Trainers-Form & & \\
\hline Confidence & 4.01 & 1.00 \\
Cultural Preference & 2.90 & 1.26 \\
Personal Openness* & 3.68 & 0.92 \\
Stigma Tolerance & 2.10 & 0.98 \\
\hline Sport Psychology Attitudes Revised-From & & \\
\hline Confidence & 4.57 & 1.12 \\
Cultural Preference & 2.82 & 1.26 \\
Personal Openness & 3.63 & 0.87 \\
Stigma Tolerance & 2.29 & 0.93 \\
\hline
\end{tabular}

*Scores were calculated in reverse coding

Table 4

Conceptions of the Nature of Athletic Ability Questionnaire-2 Cluster Means and Standard Deviations by Belief Grouping

\begin{tabular}{|ccc|}
\hline Cluster 1 "Gift-Improvement" & $M$ & $S D$ \\
\hline Stable & 2.46 & 0.85 \\
Gift & 3.13 & 0.80 \\
Learning & 3.08 & 0.66 \\
Improvement & 4.29 & 0.56 \\
\hline Cluster 2 "Learning-Improvement" & \\
\hline Stable & 1.98 & 0.63 \\
Gift & 2.49 & 0.97 \\
Learning & 4.52 & 0.45 \\
Improvement & 4.72 & 0.43 \\
\hline
\end{tabular}

\section{Profiles of Cluster Groups}

Overall, both groups scored high on the improvement subscale (see Table 4). As a whole, both groups held high incremental beliefs, but the giftimprovement group held higher entity perceptions than the learning-improvement group, as evidence by higher means on the stable and gift subscales. The main effects of beliefs concerning the nature of athletic ability (i.e., Gift-Improvement 
or Learning-Improvement) on Attitudes toward Athletic Trainers-Form subscale scores was found to be non-significant $(F(4,190)=2.37, P=.054$; Wilk's $\lambda=$ $\left..95 ; \eta^{2}=.048\right)$. However, the main effects of beliefs concerning the nature of athletic ability on the Sport Psychology Attitudes Revised-Form subscale scores were statistically significant $\left(F(4,190)=3.22, P=.014\right.$; Wilk's $\lambda=.94 ; \eta^{2}=$ $.064)$. Despite small effect size, the confidence subscale $(F(1,193)=7.66, P=$ $\left..006 ; \eta^{2}=.038\right)$ suggests that the individuals in the learning-improvement group have higher levels of confidence in their sport psychology consultant $(M=4.80$, $S D=1.12)$ compared to those in the gift-improvement group $(M=4.35, S D=$ 1.09; see Table 5 for more details).

Table 5

Athletes' Mean Attitudes Toward Athletic Trainers Form \& Sport Psychology Attitudes Revised Form Subscale Scores by Ability Beliefs

\begin{tabular}{|c|c|c|c|c|c|}
\hline & \multicolumn{2}{|c|}{$\begin{array}{l}\text { "Gift- } \\
\text { Improvement" } \\
n=98\end{array}$} & \multicolumn{2}{|c|}{$\begin{array}{l}\text { "Learning- } \\
\text { Improvement } \\
n=97\end{array}$} & \multirow[b]{2}{*}{$P$} \\
\hline Attitudes Toward Athletic Trainers Form & $M$ & $S D$ & $M$ & $S D$ & \\
\hline Confidence & 3.86 & .90 & 4.16 & 1.07 & .032 \\
\hline Cultural Preference & 3.00 & 1.14 & 2.79 & 1.36 & .227 \\
\hline Personal Openness* & 3.76 & .87 & 3.60 & .97 & .223 \\
\hline Stigma Tolerance & 2.21 & .97 & 1.98 & .98 & .101 \\
\hline Sport Psychology Attitudes Revised Form & $M$ & $S D$ & $M$ & $S D$ & $P$ \\
\hline Confidence & 4.35 & 1.09 & 4.80 & 1.12 & .006 \\
\hline Cultural Preference & 2.86 & 1.12 & 2.77 & 1.34 & .631 \\
\hline Personal Openness & 3.73 & 0.80 & 3.52 & 0.93 & .092 \\
\hline Stigma Tolerance & 2.40 & 0.93 & 2.18 & 0.92 & .089 \\
\hline
\end{tabular}

*Scores were calculated in reverse coding

\section{Previous Athletic Training Experience}

The main effects of previous experience with an athletic trainer (see Table 6 ) on the Attitudes toward Athletic Trainers-Form subscale scores were found to be statistically significant $\left(F(4,190)=2.44, P=.049\right.$; Wilk's $\left.\lambda=.95 ; \eta^{2}=.05\right)$. Further post hoc analysis revealed that the confidence subscale $(F(1,193)=6.48$, $P=.012, \eta^{2}=.032$ ) was also significant, thus suggesting that, athletes without previous experience $(M=4.37, S D=1.06)$ were more confident in their athletic trainer than athletes with previous experience $(M=3.92, S D=0.96)$. 
Table 6

Athletes' Mean Subscale Scores with and without Previous Athletic Trainer and Sport Psychology Consulting Experiences

\begin{tabular}{|c|c|c|c|c|c|}
\hline \multirow{2}{*}{$\begin{array}{l}\text { Attitudes Toward } \\
\text { Athletic Trainers Form }\end{array}$} & \multicolumn{2}{|c|}{$\begin{array}{c}\text { Experience } \\
n=157\end{array}$} & \multicolumn{2}{|c|}{$\begin{array}{c}\text { No Experience } \\
n=38\end{array}$} & \multirow[b]{2}{*}{$P$} \\
\hline & $M$ & $S D$ & $M$ & $S D$ & \\
\hline Confidence & 3.92 & 0.96 & 4.37 & 1.06 & .012 \\
\hline Cultural Preference & 2.90 & 1.24 & 2.84 & 1.24 & .771 \\
\hline Personal Openness* & 3.65 & 0.89 & 3.78 & 1.07 & .437 \\
\hline Stigma Tolerance & 2.05 & 0.96 & 2.29 & 1.04 & .181 \\
\hline & \multicolumn{2}{|c|}{$\begin{array}{c}\text { Experience } \\
n=110\end{array}$} & \multicolumn{2}{|c|}{$\begin{array}{c}\text { No Experience } \\
n=85\end{array}$} & \\
\hline \multicolumn{6}{|l|}{ Sport Psychology } \\
\hline Attitudes Revised Form & $M$ & $S D$ & $M$ & $S D$ & $P$ \\
\hline Confidence & 4.75 & 1.10 & 4.34 & 1.12 & .011 \\
\hline Cultural Preference & 2.88 & 1.21 & 2.73 & 1.27 & .390 \\
\hline Personal Openness & 3.64 & 0.84 & 3.60 & 0.92 & .805 \\
\hline Stigma Tolerance & 2.15 & 0.91 & 2.48 & 0.93 & .014 \\
\hline
\end{tabular}

*Scores were calculated in reverse coding

\section{Previous Sport Psychology Consulting Experience}

The main effects of previous experience with a sport psychology consultant (see Table 6) on the Sport Psychology Attitudes Revised-Form subscale scores were statistically significant, albeit with small effect size $(F$ (4, $190)=2.81, P=.027$; Wilk's $\left.\lambda=.94 ; \eta^{2}=.06\right)$. The results of further post hoc analyses revealed that stigmas $\left(F(1,193)=6.15, P=.014, \eta^{2}=.031\right)$ were higher for those without previous experience $(M=2.48, S D=0.93)$ compared to athletes with previous experience $(M=2.15, S D=0.91)$ however; the Bonferroni adjustment was not statistically significant. Results for confidence $(F(1,193)=$ $6.51, P=.011, \eta^{2}=.033$ ) suggested athletes with previous experience were more confident in their sport psychology consultant $(M=4.75, S D=1.10)$ than athletes without previous experience $(M=4.34, S D=1.12)$.

\section{Discussion}

This study investigated athletes' attitudes towards athletic trainers and sport psychology consultants considering the nature of athletic ability beliefs and previous experiences with the aforementioned professionals. Similar to previous research (Chian \& Wang, 2008; Wang \& Biddle, 2003), athletes in our sample predominantly held incremental (malleable) athletic beliefs. We found no significant differences between athletes' belief grouping and attitudes toward 
athletic trainers. A significant difference, albeit with small effect size, was observed among athletes' belief grouping and attitudes toward sport psychology consultants. On average, those in the gift-improvement group ranked confidence in their sport psychology consultant slightly lower than those in the learningimprovement group.

These findings provide support for the theory of planned behavior (Ajzen, 1991). The athletes who believe their athletic ability to be fixed (i.e., entity) may have perceived assistance from a sport psychology consultant as insignificant in any further development of their innate athletic ability, resulting in lower confidence in the sport psychology consultant. In contrast, athletes who believe their athletic ability to be more malleable (i.e., incremental) and a result of learned skills, may be more likely to seek out a sport psychology consultant to help further skill development. Our results also support previous research (e.g., Spray et al., 2006) in that improvement beliefs may not differ across individuals' belief structure (e.g., learning-improvement or gift-improvement).

The statistically significant relationship demonstrated among collegiate student-athletes' athletic ability beliefs and attitudes towards sport psychology consultants but not athletic trainers is interesting. Previous research by Shaffer, Tenenbaum, and Eklund (2015) found athletes' beliefs concerning mental skills ability to be influenced by entity and incremental constructs. In a controlled experiment, Shaffer et al. (2015) asked student-athletes to read an article on mental skills written from an entity or incremental belief perspective. The results revealed that athletes' post assessment of conception of mental skills ability was significantly influenced (albeit with small effect size) by the article read prior to taking the survey. It is possible, that athletes' attitudes toward sport psychology consultants, a psychological skills service provider, may have been influenced by incremental/entity beliefs of mental skills ability. In a similar manner, the athletes' attitudes toward athletic trainers, a rehabilitation service provider, may have been influenced by incremental/entity beliefs of athletic skills and/or rehabilitation skills ability. As such, the measure used in this study, which is specific to athletic ability beliefs, may not have captured the appropriate beliefs that underpin athlete's attitudes toward athletic trainers and/or sport psychology consultants.

Regardless of the above, previous research (e.g., Jowett \& Spray, 2013) and the current results suggest athletes largely believe effort and improvement are related, and those professionals working with athletes, may find praising an athlete's effort to be a beneficial motivator. Practitioners should also be mindful that athletes are likely to hold sport specific entity beliefs (Jowett \& Spray, 2013) and practice caution related to notions such as "natural talent." Consistently praising natural talent could lead to harsh reactions in the event of failure as well as amotivation in sport (Spray et al., 2006). Similarly, sport psychology 
consultants should be mindful that athletes' beliefs concerning the nature of mental skills ability may not be the same as one's conceptions of athletic abilities (Shaffer et al., 2015).

In contrast to previous research with physiotherapists in the United Kingdom (Arvinen-Barrow et al., 2012), athletes without previous experience were more confident in their athletic trainer than those with previous experience. Research has shown that collegiate athletes hold expectations about their sports medicine provider (e.g., trustworthiness, expertise) and the recovery process (e.g., outcomes, immediacy) prior to receiving any treatment (Arvinen-Barrow et al., 2016). A pre-mature expectation could have been that of a "rapid recovery" and when not met future expectations (e.g., motivation, openness) as well as the athlete's confidence in athletic trainers decreased (Clement et al., 2012). Collegiate athletes could develop a sense of entitlement, expecting readily accessible services when injured; likewise, athletes may be unfamiliar with the injury experience and lack confidence in the process (Arvinen-Barrow et al., 2016). However, as these cultural differences were not directly measured or investigated, additional research is needed in order to draw empirical conclusions.

Consistent with previous literature (Anderson et al., 2004), the relationship between previous sport psychology consultant experiences and athletes' attitudes towards sport psychology consultants were found to be statistically significant. Unlike attitudes toward athletic trainers, athletes without previous sport psychology consultation experience were less confident in sport psychology consultants' abilities to facilitate athletic performance compared to athletes with previous sport psychology consultation experience. Contradictory to previous research (Anderson et al., 2004), athletes' previous sport psychology consulting experience did not influence their stigma related attitudes. This could be due to cultural norms, where a number of myths and stigmas about sport psychology exist (Martin, 2005). Given that this was the first study to utilize the Sport Psychology Attitudes Revised-Form with collegiate athletes, further research is warranted.

The theory of planned behavior (Ajzen, 1991) presumes subjective norms (i.e., perceived social pressure) and perceived behavior control partially influence one's intentions and, in turn, behavior. When considered with the notion that athletic trainers appear to have a substantial and integral role in the collegiate athletic setting (Brumels \& Beach, 2008), whereas sport psychology consultants typically do not (Wilson, Gilbert, Gilbert, \& Sailor, 2009), the current findings are interesting. Previous research suggests injured athletes develop expectations of what the rehabilitation experience will be like and in turn, influence recovery outcomes (Clement et al., 2012). An athlete could negatively appraise both, athletic trainers themselves, and the injury rehabilitation experience. ArvinenBarrow et al. (2016) describes this inevitable pursuit as athletes' feelings of 
"entitlement" and suggests balancing treatment commitment between athletic trainers and athletes to mediate rehabilitation program expectations on part of the athlete. The same may not apply to sport psychology consultants, given their somewhat different role in collegiate settings.

Despite its merits, this study has its limitations. Convenience sampling allowed for assessment of NCAA Division II collegiate athletes, but results may not be generalizable to other settings. Previous research found student-athletes' athletic training and sport psychology consultation experiences to be associated with student-athletes' expectations of these professionals. Thus, it is likely that the exposure to the athletic trainers and the sport psychology consultants working in this institution may have shaped the attitudes and beliefs of the participants prior to data collection (Clement et al., 2012; Wrisberg, Simpson, Loberg, Withycombe, \& Reed, 2009). Similarly, it is possible that athletes' demographics influenced attitudes in the similar manner that they have been found to influence expectations about physiotherapists (Arvinen-Barrow et al., 2016), and attitudes towards sport psychology consultants (Lavallee et al., 2005). Also, data with regards to athletes' coincidental treatment or consultation services with an athletic trainer or sport psychology consultant at the time of data collection was not collected. It is therefore not known if and how such services influenced the attitudes, thus warranting further research. Additionally, 50\% of the sample reported having previous sport psychology consulting experience, which is higher than the typical collegiate student-athlete experience (Wilson et al., 2009). It is not known if this, along with the lead researcher being a practicing athletic trainer at the institution, increased the potential for response bias.

Also, the internal consistency of the Conceptions of the Nature of Athletic Ability Questionnaire-2 stable $(\alpha=.61)$ and personal openness subscales of the Attitudes toward Athletic Trainers-Form $(\alpha=.64)$ and Sport Psychology Attitudes Revised-Form $(\alpha=.57)$ are low. Despite research supporting subscales comprised of approximately five items or less being potentially reliable with low Cronbach's alpha coefficients ( $\alpha<7$; Morera \& Stokes, 2016), one should utilize the above scales with caution when interpreting results of the current study.

Regardless of the above limitations, this study can be of benefit to both athletic trainers and sport psychology consultants. Practitioners typically do not evaluate athletes' attitudes prior to working with them (Martin, 2005). However, being aware of athletes' attitudes and expectations prior to treatment or consultancy may be beneficial for practitioners, particularly when gaining entry and building trust and rapport (Clement et al., 2012; Martin et al., 2001). Trust may enable practitioners to better comprehend athletes' reactions during the rehabilitation process facilitating care (Clement et al., 2012). Establishing a relationship built on trust has been shown to increase athletes' treatment satisfaction (Clement \& Shannon, 2011). This may lead to athletes' development 
of positive attitudes toward athletic trainers and sport psychology consultants subsequently, enhancing the quality of the working relationship between the athlete and the professional. Still, the aforementioned results and discussion are preliminary requiring cautious interpretation and additional research before making empirical claims.

\section{Conclusions}

The results of this study suggest athlete attitude development is influenced, in part, by previous experiences and personal athletic ability beliefs. The results also support the theory of planned behavior (Ajzen, 1991) in that athletes' attitudes toward athletic trainers and sport psychology consultants are likely influenced by subjective norms. Future researchers should explore collegiate athletes' attitudes and expectations in lieu of subjective norms. Be it as it may, athletic trainers and sport psychology consultants may be seen as impartial to the athletic environment athletes train in. In order to facilitate positive changes in athlete behavior, understanding athlete attitudes is of importance. However, considering the small effect sizes found in the current study, future research is warranted before any conclusive recommendations can be made.

\section{References}

Anderson, A. G., Hodge, K. P., Lavallee, D., \& Martin S. B. (2004). New Zealand athletes' attitudes towards seeking sport psychology consultation. New Zealand Journal of Psychology, 33(3), 129-136.

Arvinen-Barrow, M., Clement, D., \& Bayes, N. (2012). Athletes' attitudes toward physiotherapist: An exploratory investigation. International Journal of Multi-Disciplinary Studies and Sports Research, 2, 324-334.

Arvinen-Barrow, M., Clement, D., Hamson-Utley J. J., Kamphoff C., Zakrajzek R., Lee S- M., ... Martin, S. B. (2016). Athletes' expectations about sport injury rehabilitation: A cross-cultural study. Journal of Sport Rehabilitation, 25(4), 338-347. https://doi.org/10.1123/jsr.2015-0018

Ajzen, I. (1991). The theory of planned behavior. Organizational Behavior and Human Decision Processes, 50(2), 179-211. https://doi.org/10.1080/08870446.2011.613995

Ajzen, I. (2011). The theory of planned behavior: Reactions and reflections. Psychology and Health, 26(9), 1113-1127. https://doi.org/10.1080/08870446.2011.613995

Barnard, J. (2016). Student-athletes' perceptions of mental illness and attitudes toward help-seeking. Journal of College Student Psychotherapy, 30(3), 161-175. https://doi.org/10.1080/87568225.2016.1177421 
Biddle, S. J. H., Wang, J. C. K., Chatzisarantis, N. L. D., \& Spray, C. M. (2003). Motivation for physical activity in young people: Entity and incremental beliefs about athletic ability. Journal of Sports Sciences, 21(12), 973-989. https://doi.org/10.1080/02640410310001641377

Brumels, K., \& Beach, A. (2008). Professional role complexity and job satisfaction collegiate certified athletic trainers. Journal of Athletic Training, 43(4), 95-105. https://doi.org/10.4085/1062-6050-43.4.373

Chian, L. K. Z., \& Wang, C. K. J. (2008). Motivational profiles of junior college athletes: A cluster analysis. Journal of Applied Sport Psychology, 20(2), 137-156. https://doi.org/10.1080/10413200701805265

Clement, D., Hamson-Utley, J., Arvinen-Barrow, M., Kamphoff, C., Zakrajsek, R., \& Martin, S. (2012). College athletes' expectations about injury rehabilitation with an athletic trainer. International Journal of Athletic Therapy and Training, 17(4), 18-27. https://doi.org/10.1123/ijatt.17.4.18

Clement, D., \& Shannon, V. (2011). Injured athletes' perceptions about social support. Journal of Sport Rehabilitation 20(4), 457-470. https://doi.org/10.1123/jsr.20.4.457

Eagly, A., \& Chaiken, S. (1993). The psychology of attitudes. Orlando, FL: Harcourt Brace Jovanovich College Publishers.

Filion, S., Munroe-Chandler, K., \& Loughead, T. (2019). Psychological skills used by sport psychology consultants to improve their consulting. Journal of Applied Sport Psychology, 0, 1-19. https://doi.org/10.1080/10413200.2019.1647475

Fortin-Guichard, D., Boudreault, V., Gagnon, S., \& Trottier, C. (2018). Experience, effectiveness, and perceptions toward sport psychology consultants: A critical review of peer-reviewed articles. Journal of Applied Sport Psychology, 30(1), 3-22. https://doi.org/10.1080/10413200.2017.1318416

Granquist, M. \& Brewer, B. (2013). Psychological aspects of rehabilitation adherence. In M. Arvinen-Barrow \& N. Walker (Eds.), The Psychology of Sport Injury and Rehabilitation (pp. 40-53). Abingdon: Routledge.

Hair, J. F., Black, W. C., Babin, B. J., \& Anderson, R. E. (2010). Cluster analysis. In Heine. J. (Ed.), Multivariate Data Analysis (pp 483-542). Upper Saddle River, NJ: Prentice Hall

Harwood, C. G., \& Woolway, T. (2015). Do titles matter in sport psychology? Performer attitudes toward professional titles and the effect of a brief intervention. The Sport Psychologist, 29(2), 171-182. https://doi.org/10.1123/tsp.2014-0050

Hilliard, R., Blom, H., Hankemeier, D., \& Bolin, J. (2016). Exploring the relationship between athletic identity and beliefs about rehabilitation 
overadherence in college athletes. Journal of Sport Rehabilitation. Advance online publication. https://doi.org/10.1123/jsr.2015-0134

Hilliard, R., Redmond, L., \& Watson, J. (2019). The relationships among selfcompassion, stigma, and attitudes toward counseling in student-athletes. Journal of Clinical Sport Psychology, 13(3), 374-389. https://doi.org/10.1123/jcsp.2018-0027

Hobbs, C., Nahar, V., Ford, A., Bass, M., \& Brodell, R. (2014). Skin cancer knowledge, attitudes, and behaviors in collegiate athletes. Journal of Skin Cancer, 1-7. https://doi.org/10.1155/2014/248198

Jowett, N., \& Spray, C. (2013). British Olympic hopefuls: The antecedents and consequences of implicit ability beliefs in elite track and field athletes. Psychology of Sport and Exercise, 14(2), 145-153. https://doi.org/10.1016/j.psychsport.2012.09.003

Lavallee, D., Jennings, D., Anderson, A, \& Martin, S. (2005). Irish athletes' attitudes toward seeking sport psychology consultation. Irish Journal of Psychology, 26(4), 115-121. https://doi.org/10.1080/03033910.2005.10446214

Martin, S. B. (2005). High school and college athletes' attitudes toward sport psychology consulting. Journal of Applied Sport Psychology, 17(2), 127139. https://doi.org/10.1080/10413200590932434

Martin, S. B., Akers, A., Jackson A., Wrisberg, C., Nelson, L., Leslie, J., \& Leidig, L. (2001). Male and female athletes' and nonathletes' expectations about sport psychology consulting. Journal of Applied Sport Psychology, 13(1), 18-39. https://doi.org/10.1080/104132001753155930

Martin, S. B., Kellman, M., Lavallee, D., \& Page, S. J. (2002). Development and psychometric evaluation of the sport psychology attitudes- revised from: A multiple group investigation. The Sport Psychologist, 16(3), 272-290. https://doi.org/10.1123/tsp.16.3.272

Martin, S. B., Lavallee, D., Kellman, M., \& Page, S. J. (2004). Attitudes toward sport psychology consulting of adult athletes from the United States, United Kingdom, and Germany. International Journal of Sport and Exercise Psychology, 2(2), 146-160. https://doi.org/10.1080/1612197x.2004.9671738

Martin, S. B., Wrisberg, C. A., Beitel, P. A., \& Lounsbury, J. (1997). NCAA division I athletes' attitudes toward seeking sport psychology consultation: The development of an objective instrument. The Sport Psychologist, 11(2), 201-218. https://doi.org/10.1123/tsp.11.2.201

Moreno-Murcia, J. A., Gimeno, E. C., Galindo, C. M., Hernández, E. H., \& Buñuel, P. S. (2014). Conceptions of the ability and self-determined motivation in young Spanish athletes. Psicologia: Reflexão e Crítica, 27(3), 515-521. https://doi.org/10.1590/1678-7153.201427312 
Morente-Sanchez, J., \& Zabala, M. (2013). Doping in sport: A review of elite athletes' attitudes, beliefs, and knowledge. Sports Medicine, 43(6), 395411. https:// doi.org/10.1007/s40279-013-0037-X

Morera, O., \& Stokes, S. (2016). Coefficient $\alpha$ as a measure of test score reliability: Review of 3 popular misconceptions. American Journal of Public Health, 106(3), 458-461. https://doi.org/10.2105/AJPH.2015.302993

Rich, A., Brandes, K., Mullan, B., \& Hagger, M. (2015). Theory of planned behavior and adherence in chronic illness: A meta-analysis. Journal of Behavioral Medicine 38, 673-688. https://doi.org/10.1007/s10865-0159644-3

Sande-Meijide, M., Lorenzo-Gonzalez, M., Mori-Gamarra, F., Cortes-Gago, I., Gonzalez-Vazquez, A., Moure-Rodríguez, L., \& Herranz-Urbasos, M. (2019). Perceptions and attitudes of patients and health care workers toward patient empowerment in promoting hand hygiene. American Journal of Infection Control 47, 45-50. https://doi.org/10.1016/j.ajic.2018.07.002

Shaffer, C. T., Tenenbaum, G., \& Eklun, R. C. (2015). Implicit theories of mental skills abilities in collegiate athletes. Journal of Applied Sport Psychology 27(4), 464-476. https://doi.org/10.1080/10413200.2015.1044136

Spray, C. M., Wang, C. K. J., Biddle, S. J. H., Chatzisarantis, N. L. D., \& Warburton, V. E. (2006). An experimental test of self-theories of ability in youth sport. Psychology of Sport and Exercise, 7(3), 255-267. https://doi.org/10.1016/j.psychsport.2005.05.001

Tsimtsiou, Z., Kirana, P., \& Hatzichristou, D. (2014). Determinants of patients' attitudes toward patient-centered care: A cross-sectional study in Greece. Patient Education \& Counseling, 97, 391-395. https://doi.org/10.1016/j.pec.2014.08.007

Wang, C. K. J., \& Biddle, S. J. H. (2003). Intrinsic motivation towards sports in Singaporean students: The role of sport ability beliefs. Journal of Health Psychology, 8(5), 515-523. https://doi.org/10.1177/13591053030085004

Wang, J., \& Koh, M. (2006). Sport ability beliefs, achievement goals, selfdetermination and beliefs about the purpose of physical education among Singaporean preservice education trainees. Asian Journal of Exercise \& Sports Science, 3(1), 25-34. Retrieved from: http://hdl.handle.net/10497/13685

Wilson, K., Gilbert, J., Gilbert, W., \& Sailor, S. (2009). College athletic directors' perceptions of sport psychology consulting. The Sport Psychologist, 23(3), 405-424.

Wrisberg, C., Simpson, D., Loberg, L., Withycombe, J., \& Reed, A. (2009). NCAA division-I student-athletes; receptivity to mental skills training by 
sport psychology consultants. The Sport Psychologist, 23, 470-486. https://doi.org/10.1123/tsp.23.4.470

Wyer, S. J., Earll, L., Joseph, S., \& Harrison, J. (2001). Deciding whether to attend a cardiac rehabilitation programme: An interpretive phenomenological analysis. Coronary Health Care, 5(4), 178-188. https://doi.org/10.1054/chec.2001.0136

Zang, Z. (2016). Missing data imputation: Focusing on single imputation. Annals of Translational Medicine, 4(1), 1-21.

http://dx.doi.org/10.3978/j.issn.2305-5839.2015.12.38 